\title{
Anemia in the Problem of Morbidities in Reproductive Health in Côte d'Ivoire
}

\author{
Adou Serge Judicaël ANOUA ${ }^{1^{*}}$
}

${ }^{1}$ Department of Anthropology \& Sociology, Alassane Ouattara University, Bouaké, Côte d'Ivoire

DOI: $10.36347 /$ sjahss.2021.v09i02.003

| Received: 09.02.2021 | Accepted: 22.02.2021 | Published: 23.02.2021

*Corresponding author: Adou Serge Judicaël ANOUA

Abstract

Original Research Article

Anemia in pregnant women is an issue of concern even in urban areas. The city of Bouake in Côte d'Ivoire is no exception to this prevalence of anemia in pregnant women. This morbidity during pregnancy remains a risk basis for the survival of the mother-child relationship. Although it is admitted that several works according to various fields of research have been conducted to identify the causes, the consequences and the means of prevention of this morbid fact, it is nonetheless true to take into account the social perceptions that - extend this reality. This research aims to specify the explanatory model of anemia in pregnant women in order to contribute to the control of this disease during the prenatal period. An ethnographic study supported by a semi-structured interview supported by structured questions on perceptions and attitudes related to anemia targeted pregnant women in consultation at Ahougnanssou urban health center, so as to explain the characters of this morbidity through the mode of thought relating to this social group. Pregnant women interviewed equate anemia with blood deficiency in the body. This predisposes them to the risk of obstetric complications and mortality. They also agree that the lack of financial resources is the key factor in the exposure to anemia. Beyond this financial factor, they explain this morbidity through the irregular monitoring of pregnancy, while inappropriate dietary habits are the complementary explanatory factor for these women. The recurring risk factors associated with anemia among pregnant women in this research require a solution approach that takes into account social relevance. This logic should lead to changes in the provision of antenatal care and help reduce the vulnerabilities of pregnant women in the fight against this indirect cause of maternal mortality.

Keywords: Anemia, Morbidities, Reproductive.

Copyright (C) 2021 The Author(s): This is an open-access article distributed under the terms of the Creative Commons Attribution 4.0 International License (CC BY-NC 4.0) which permits unrestricted use, distribution, and reproduction in any medium for non-commercial use provided the original author and source are credited.

\section{INTRODUCTION}

Anemia is a worrying morbidity in reproductive health. Indeed, it affects $38 \%$ of pregnant women aged 15 to 49 worldwide. Its persistence is increasingly noticed with a prevalence greater than $50 \%$ in South Asia, Central Africa and West Africa [1]. This magnitude is made more complex due to the vulnerability of the pregnant woman and her child. In Côte d'Ivoire, among pregnant women, the proportion of those with anemia is $64 \%$ with a maximum prevalence of $75 \%$ in the Center-North region [2]. In this region, the city of Bouaké is no exception to the prevalence of anemia among pregnant women. This morbidity during pregnancy remains as a risk base for the survival of the mother-child couple. If it is admitted that several works according to various fields of research have been carried out to identify the causes, the consequences and the means of prevention of this morbid fact, it nevertheless remains to take into account the social perceptions which under tend this reality.
This research aims to specify the explanatory model of anemia in pregnant women in order to contribute to the control of this disease during the prenatal period.

\section{METHODOLOGY}

Our qualitative research is based on an anthropological approach [3]. It was carried out at the Ahougnansou urban health center in the city of Bouaké in Côte d'Ivoire, in July 2019. Pregnant women in consultation in this health structure were the criteria for including people to be interviewed afterwards, with their verbal consent and using a systematic random sampling technique. A semi-structured group interview supported by structured questions on perceptions related to anemia was conducted. Two essential questions were asked: "What is said about anemia in pregnant women? "; "What does anemia in pregnant women reminds you of?" ". A content analysis [4] was carried out using structured discourse on social perception and the explanatory factors for anemia. The profane theories 
constructed were used to give meaning to the logic of the respondents in order to offer levers for a solution to this morbidity.

\section{RESULTS}

The results of this research present the social perceptions and explanatory factors related to anemia in pregnant women at the Ahougnansou urban health center in the city of Bouaké in Côte d'Ivoire.

\section{Social perceptions of anemia in pregnant women}

The group of pregnant women interviewed viewed anemia as a blood-related illness. According to them, a person with anemia is a person who lacks blood or has insufficient blood in his body.

In addition, the group of pregnant women interviewed pointed to several signs of manifestations of anemia. These include fever, dizziness, fatigue, and lack of appetite, pallor of the face, eyes, palm, soles and leanness. For them singularly, the state of pallor represents the stage of gravity in the evolution of this affection.

For the group of pregnant women interviewed, the alleged causes of anemia were attributed to an unvarying diet due to the dietary restrictions of the custom of belonging. Added to this is the lack of use of iron supplements at the health center and intense physical activity during pregnancy, which causes gestation fatigue.

Following these social perceptions, the social determinants of anemia in pregnant women need to be examined.

\section{Social determinants of anemia in pregnant women}

The group of pregnant women interviewed noted three explanatory factors for anemia. First, the group of pregnant women interviewed noted that pregnant women are not responsible for taking iron supplements. Refusal of these medical products is linked to their side effects including nausea, vomiting and debility.

Next, the group of pregnant women interviewed suggested that irregular antenatal care was linked to the development of anemia. Since their absence from antenatal visits does not allow them to have edifying access to advice on dealing with anemia. These pregnant women are thus willingly exposed to this morbidity.
Finally, the group of pregnant women interviewed noted that the lack of financial resources was a constraint in the face of avoiding anemia. This is due to the difficulties in regulating prescriptions for iron supplement medical products but also in providing an adequate diet.

\section{Implications}

The recurrent risk factors associated with anemia in pregnant women require consideration of social relevance in order to induce changes in the prenatal care offer and to help reduce the vulnerabilities of pregnant women.

\section{CONCLUSION}

Anemia in pregnant women should not be thought of around the curative and the organic. The social and mental dimensions influence physical health as well as the health of pregnant women. Anemia is a health problem to be observed in the socio-cultural environment that underpins it. Human behavior is an essential underlying factor. On the other hand, looking for appropriate and effective solutions over the long term to this public health problem requires immersion of midwives in the life of pregnant women. This involves learning them from an anthropological approach with a view to strengthening skills through added value linked to mastering the socio-cultural environment. The increase in midwifery's professional performance is a guarantee of efficiency.

\section{REFERENCES}

1. WHO. Global nutrition targets 2025: anaemia policy brief. Genève: World Health Organisation. 2017; (WHO/NMH/NHD/14.4). Licence: CC BYNC-SA 3.0 IGO.

2. Ministère de la Santé et de l'Hygiène Publique (MSHP). Plan national de développement sanitaire 2016-2020. [National Health Development Plan 2016-2020]. Abidjan, République de Côte d'Ivoire: Draft Consolidé. 2016; 1-88. https://www.childrenandaids.org/sites/default/files/ 2017-11/pnds_2016-2020.pdf

3. Thorne SE. Interpretive Description. Walnut Creek: Left Cost Press; 2008.

4. Paillé, et Mucchielli A. L'analyse qualitative en sciences humaines et sociales. [Qualitative analysis in the humanities and social sciences] 3e éd. Paris: Armand Colin. 2012; 1-424 https://www.cairn.info/l-analyse-qualitative-ensciences-humaines--9782200249045.htm 